\title{
“积极设计”营造康体城市 支持健康生活方式的城市规划设计新视角
}

\author{
Building an Active City with Active Design: \\ A New Perspective of Urban Planning and Design Supporting Healthy Living
}

萧明

Xiao Ming

\begin{abstract}
摘要: 本文介绍了西方在全球性健康城市 运动背景下出现的一个新的规划视角— 支持积极生活方式的积极城市规划与设计。 从交通与用地、公共开放空间、建筑设计、 健康食物、环境评估等方面分别论述了主要 的设计原则和相关做法, 并针对中国国情提 出了借鉴性的思考。
\end{abstract}

Abstract: This paper introduces a new perspective of urban study in the context of global Healthy City Movement, which is to support active living via active urban planning and design. It discusses primary design principles and planning implementation in terms of transportation, land use, open space, architectural design, healthy food, environmental evaluation and etc. It also proposes the ideas that apply active planning and design to China's urban development based on international experience.

关键词：健康城市；康体城市； 积极的城市规划设计; 积极的生活方式

Keywords: Healthy City; Active City; Active Urban Planning and Design; Active Living

江苏省政府留学奖学金 (2011) 资助
西方城市发展历史中, 公共健康与城市规划经历了合作一分离一合作的历程。 从 19 世纪下半叶至 20 世纪早期, 西方城市经历了无序扩张、人口聚集、城市环境 恶化并导致各种流行病爆发的时期。人们采取各种措施改善城市环境, 战胜传染疾 病, 如建设排水系统、城市公园, 确立新住房规范, 以及设立旨在保证建筑卫生和 防火间距的区划法等。在城市规划解决了最初的基本卫生和疾病问题之后, 公共健 康的关注点从卫生设施转向医疗事业, 公共健康的实践也从社会模式转向医学模式。 经过约半个世纪的医学模式实践, 从 20 世纪 80 年代起, 公共健康从业人员发现, 人们的健康除了与个人身体机能和特定免疫能力有关之外, 环境、社会因素起到更 为关键的作用, 将公共健康问题全盘交予医疗卫生部门是非常局限的。人们对健康 的定义也较以往有了大幅的扩展：“健康是所有身体的、精神的、社会的良好状态， 而不仅仅是没有病残。” ${ }^{[1]}$ 健康观念的转变迫使公共健康又在更高的层面从医学模 式回归到社会模式。

1979 年发布的《2000 年世界全民健康战略》提出, 改善人民健康和福利状况 的主要领域, 并非健康部门本身, 还应包括称城市、区域乃至国家、国际层面的许 多其他部门。1986 年加拿大渥太华的第一届国际健康促进大会上通过了著名的《健 康促进渥太华宪章》, 深人阐述了健康的公共政策属性、生态支持条件、社区自治 手段、个人健康教育以及医疗卫生转向全面的社会服务等原则和观点。其中城市规 划是重要的健康促进部门之一。

1986 年, 世界卫生组织首次设立 “健康城市工程项目” 以推进新健康观念的传 播,促进《健康促进渥太华宪章》在地方政府层面的实施。1998年在雅典召开的“健 康城市国际会议” 标志着健康城市运动已经成为一个全球性的运动。其中, 健康城 市 (Healthy City) 是作为一个过程而非结果来界定的, 它不是一个已达到特定健康 水平的城市, 而是对健康有清醒认识、并努力对其进行改善的城市 ${ }^{[2]}$ 。健康城市所 具有的 11 项特征包含 : 高质量且安全的物理环境、可持续的生态系统、人们之间 稳固的相互支持的社会关系、公众对于健康的高度参与和控制权、城市满足居民的 所有需求、居民获得广泛多样的城市体验和资源、城市多样而有活力的创新精神、 文化传统、兼容模式、卫生服务的适宜标准, 以及城市人民的较高健康水平 ${ }^{[3]}$ 。

作者: 萧明, 江苏省城市规划设计研究院城市设计所, 高级城市规划师; 加拿大曼尼托巴大学城市规划系, 访问学者。Maureen_xiao@aliyun.com 


\section{1 康体城市 ( active city)、积极生活方式 ( active living) 和积极的城市规划设计 ( active city planning and design )}

健康城市运动深刻影响了从城市公共政策到健康卫生再 到城市规划管理等各个领域的工作方式和研究方向。在这样 一个大背景下, 城市规划和设计领域从 “建成环境如何影响 公众健康” 的角度人手, 通过与社会其他部门的联合和跨学 科研究合作, 形成了相当丰富的理论和实践成果。其中, 康 体城市是其中一个被广为接受的概念。康体城市是指能让人 提高身体活动性（physical activity）的城市, 是通过物质环 境的设计和改善, 帮助人们增加日常活动量和专门运动的机 会, 从而提高全社会整体的身体健康水平。康体城市是在健 康城市的范畴和框架下, 为提升健康水平而做出努力的一个 思路和方面, 与健康城市有联系也有区别。康体城市与城市 物质空间形态和设计密切相关。作为建筑师、城市规划师、 交通规划设计师等专业人士, 可以通过本职工作改善城市物 质环境, 达到帮助人们提高身体活动性, 进而提高城市整体 健康水平的目的。

有研究表明, 在美国的城市总体规划中涉及到的健康主 题，包括积极生活方式、环境健康、安全、气候、卫生服务、 社会健康、食品、营养和慢性病。其中涉及最多的是积极生 活方式的讨论（占 $57 \%)^{[4]}$ 。

积极生活方式的概念源于目前西方城市过多依赖机动车 交通、个人身体运动大幅减少、久坐的生活方式迅速曼延,
从而造成肥胖症、心血管疾病、糖尿病等慢性疾病逐年增长。 尤其在北美地区, 低密度的城市蔓延所造成的能源、社会、 健康问题尤为严重。有数据显示, 1990-2007 年, 美国肥胖 症的发病率从 $20 \%$ 以下迅速增长到 $20 \%$ 30\%。纽约市大部分 成年人和 $43 \%$ 的小学生都达到超重或者肥胖状态 ${ }^{[5]}$ 。加拿大 每 4 个成年人中就有 1 人体重超标, 儿童肥胖症在过去 25 年 翻了 3 倍。加拿大全国肥胖发病率趋势如图 1 所示, 可见尽 管采取了多种措施加以控制, 但加拿大各省的肥胖症发病率 在 2000-2010 年间总体仍呈上升趋势。2011 年大部分省的肥 胖症发病率均在 $25 \%$ $35 \%$ 之间。在欧洲, 15 岁以上的欧盟 国家居民, 有 $2 / 3$ 的人未达到推荐的运动水平。每年由于缺 乏锻炼造成的死亡人数预计高达 60 万人 ${ }^{[6]}$ 。同时, 慢性病患 病率的增加也大大加重了财政负担, 造成了严重的经济问题。 更为让人担忧的是, 这种问题随着全球其他地区城市化水平 的进一步提升和机动车交通主导地位的确立, 在更多的国家 和地区蔓延开来。

所谓积极的生活方式, 就是相对于久坐, 增加身体活动, 并将身体锻炼融人日常生活的一种生活方式。人们可以通过 不同的途径达到每天至少 30 分钟身体活动的积极生活目标, 正式和非正式均可。如步行或骑自行车、进行健身活动、参 加体育运动、在公园玩要、在花园里劳动、爬楼梯等等。在 城市环境中通过城市规划设计来支持这种生活方式，鼓励人 们增加运动量, 提高身体机能, 增进健康水平, 这就是康体 城市的由来。

围绕营造积极生活方式产生了 “积极的城市规划设计”
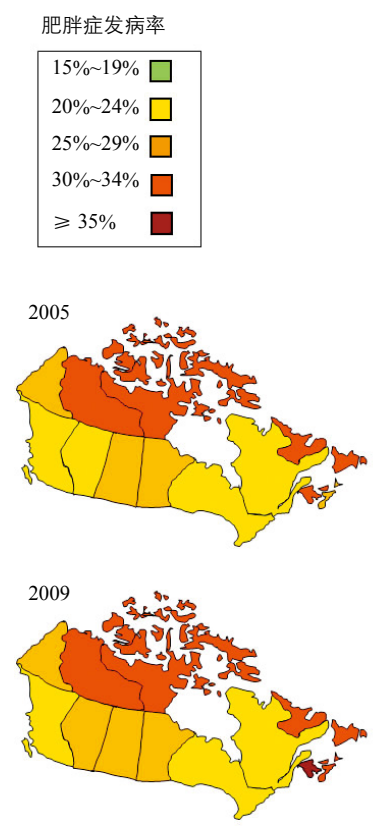
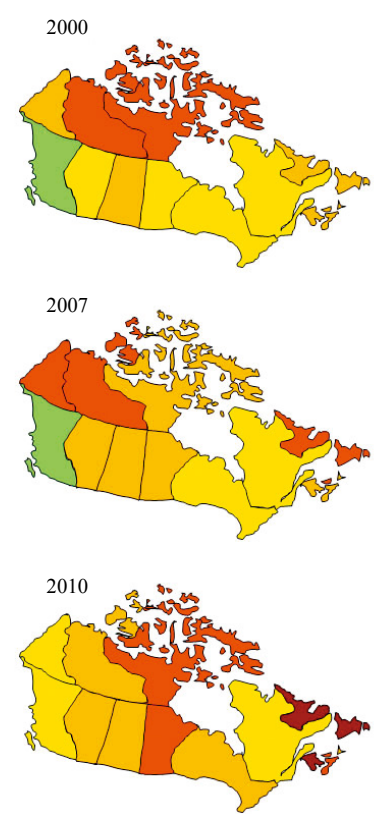
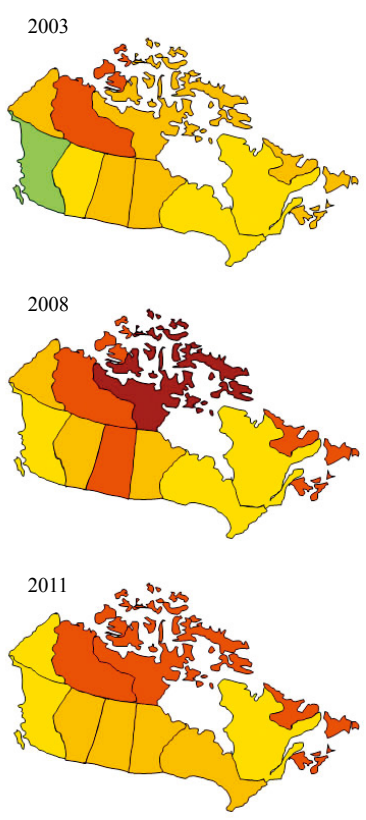

图 1 加拿大全国肥胖症发病率统计

资料来源 : http://www.epodecanada.ca/wp-content/uploads/2014/07/Updating-the-Canadian-Obesity-Maps-An-Epidemic-in-Progress-Gotay-2013.pdf 
(active city planning and design)。所谓 “积极的城市规划设 计” 并非一种新兴的规划理论和方法, 而是强调健康问题导 向的思路, 从增加人们日常身体活动、增进人们的整体身心 健康水平的具体目标出发, 在城市规划和设计的方方面面进 行反思和探讨, 明确目前的城市环境对积极生活方式的威胁, 从而切实地改善建成环境, 达到促进公共健康、提高生活品 质的目的。对于积极的城市规划和设计, 本文以下内容将分 别从用地与交通、公共空间设计、建筑设计、健康食品等领 域进行详细论述。

\section{2 积极的用地与交通规划}

积极的交通方式（active transportation）是指任何人 们利用自己的体力进行移动的方式, 如步行、自行车、轮 椅, 甚至滑板等, 有时被称为替代交通方式 (alternative transportation)。因为这个概念最开始是针对私人机动车占绝 对主导地位的城市交通而言的。然而相对于后者, 积极的交 通方式无污染, 有利于增进健康和社会交往, 同时更加兼顾 社会公平, 如今已成为西方城市规划一致推崇的一种交通方 式。2012 年以前, 为发展中国家提供资金支持的国际发展 银行往往倾向于投资汽车导向的高速公路、高架路等; 2012 年 6 月在里约热内卢举行的联合国可持续发展会议上, 世界 最大的多国发展银行 (MDB) 如世界银行、亚洲发展银行、 美洲发展银行等, 承诺在 10 年内提供超过 17.5 亿美元的资 金用于可持续和积极的交通发展, 扭转一直以来汽车导向的 交通发展趋势 ${ }^{[4] 35}$ 。可见积极的交通方式已在全球范围内得 到高度认同。推动积极交通方式的举措包括混合利用土地, 优化步行和自行车环境, 大力发展公共交通, 以及调整停车 策略等。

\section{1 紧凑混合的用地方式}

北美目前普遍面临低密度郊区化曼延的现状 : 居住区功 能单一, 以单一家庭为主的住房造成城市密度过低, 社区环 境单调无活力。居民要解决日常生活需求如去超市、邮局等 都必须依赖私人小汽车出行。相反, 多样化的用地模式使人 们更倾向于步行解决日常生活所需。例如, 将学校、邮局、 杂货店放置在社区的步行距离范围内; 另外适当提高社区开 发密度, 进行更多的 “填充式” 开发 (infill development) 以增加住房的多样性, 兼顾多种家庭结构、经济水平和年龄 层次人群的需求, 有利于更多的资源共享和社会交往, 也鼓 励更多的身体活动。同时, 将居住和工作区域安排在目的地 附近（如公园、步道、水岸休闲空间等）能够鼓励更多的身 体活动和锻炼。

\section{2 普遍可达的步行环境}

研究表明, 更小尺度的街区（通常在 $100 \mathrm{~m}$ 以下）能够 带来更好的街道连接性, 更利于鼓励行人步行。当大尺度街 区已经形成时, 可提供穿越地块的步行线路, 方便行人使用; 尽量避免行人过街天桥或者地道这种迫使行人转换高度的设 施, 避免对行人造成障碍。在机动车尽端路为步行提供可穿 越的线路。在通往目的地的路线上设计普遍可达的步行环境, 保证人行道的宽度, 设置清晰安全的过街标识、由行人启动 的交通信号灯, 以及充足的街道照明等。考虑轮椅和滑板、 溜冰鞋的需求, 设置无障碍坡道等设施。利用稳静化措施提 高步行环境的整体安全性, 包括减少机动车道数量和宽度、 增加地面标识、营造中心岛以及设置限速装置等。

由于西方国家整体进人了对机动车主导交通的反思阶 段, 所以包括行人和自行车在内的慢行交通受到前所未有的 重视, 并出现了一股 “行人夺回路权” (Reclaim the Rightof-Way）的风潮。为了行人的安全, 机动车道变得越来越窄

(Skinny Street), 在道路交叉口或者吸引人流汇集的地方设 置了加宽的人行道 (Curb Extensions)（图 2)。如今已从满 足行人步行的安全性发展到追求步行环境的宜人、舒适。许 多城市步行道上开始设置座椅、饮用水处、则所、自行车架 等设施, 并设置公共艺术作品。很多鼓励步行的城市活动也 相应展开, 如机动车禁止通行的街道封闭日、慈善步行活 动、纪念简·雅各布斯的 “简之行” (Jane's Walk) 等 (图 3)。 相当具有代表性的是一个名叫 “Park(ing) Day” 的活动。这 是一个美国旧金山设计事务所发起的将路边计时停车位临时 改造成各种适宜人们社会活动的场所的活动, 自 2005 年开 始后迅速传遍世界。受此活动影响, 旧金山市在 2010 年已 经开始出现将路边停车位永久性改造成为行人休憩设施的停 车位公园 (Parklet) 计划（图 4), 行人有了更多的步行、休 闲、玩要的空间。

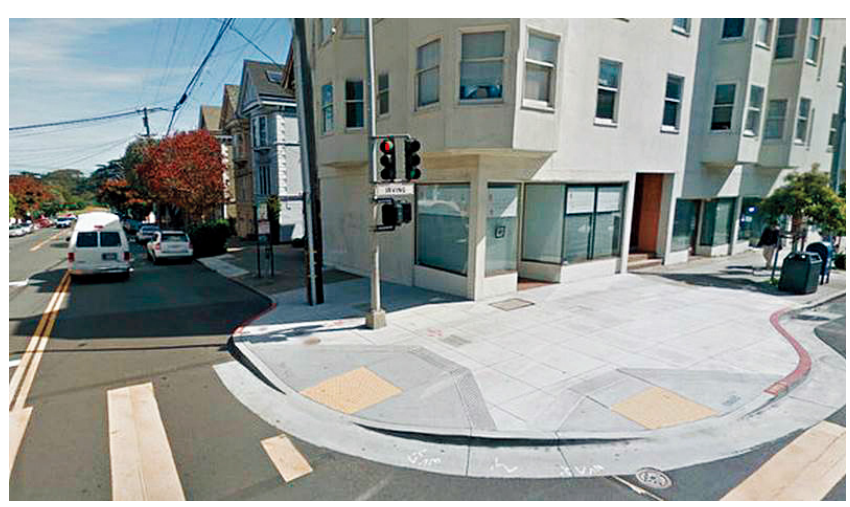

图 2 美国旧金山市一处加宽的人行道

资料来源 : http://sf.streetsblog.org/category/issues-campaigns/bus-bulb/ 


\section{3 完善的自行车体系}

在中国城市越来越多地以汽车代替自行车作为主要出行 工具的同时, 西方国家兴起了与此截然相反的自行车出行的 热潮。研究表明, 在美国, 自行车是增长最迅猛的交通方式。 城市交通体系也开始形成完善、安全、高效的自行车道路和 设施体系。纽约市自 2007 年以来, 已建成一个 280 英里（约 $450 \mathrm{~km})$ 的自行车网络。美国加州圣莫妮卡地区建有两个 “自行车中心”, 包括淋浴设施、储物柜、自行车存放设施、 旅游服务、零售业、自行车修理店等内容。“自行车中心” 在大幅促进市中心的自行车出行率的同时, 成为新的旅游集 散点并为城市增添约 10 万美元的公共财政收人 ${ }^{[4] 39}$ (图 5)。 在加拿大, 自行车道与机动车分离并被显著标识, 在交叉口 进行特殊处理, 保障自行车的交通安全（图 6, 图 7), 在其 他国家及地区亦存在类似做法。英国建成贯穿全国的“国家 自行车网络” (National Cycle Network)。国家自行车网络的 $70 \%$ 设于经过处理减少自行车与机动车接触的道路上, 其余 路段使用人行通路、废弃的铁路、较小的道路进行贯通。国 家自行车网络的首段于 1984 年开通, 截至 2014 年, 已有 $23700 \mathrm{~km}$ 符合标准的自行车道投入使用。
自 20 世纪 60 年代公共自行车系统由丹麦哥本哈根首创 之后, 如今已影响到 49 个国家的超过 500 个城市。公共自 行车增强人们使用自行车的灵活性, 缓解交通阻塞, 降低空 气污染, 支持本地商业。从 2007 年起, 公共自行车在全世 界的影响力大大提升。杭州市于 2008 年在中国率先实施了 公共自行车项目, 并成为全世界规模最大的公共自行车项目 之一, 保有约 7 万辆公共自行车, 其重点在于与公交系统配 合, 解决公交站点到目的地的 “最后一英里” 问题。杭州市 政府预期公共自行车数量在 2020 年达到 17.5 万辆 ${ }^{[4] 40}$ 。

\section{4 公共交通和停车策略}

公共交通包括地铁、轻轨、公交巴士、渡轮、街车、共 乘 (vanpool) 等。一项研究表明, 美国北卡罗来纳州的夏洛 特市（Charlotte）的公交使用者比开车通勤的人患肥胖症的 几率要低 $81 \%$ 。调查表明, 美国成人有 $51 \%$ 更倾向于居住 在公交方便的社区中。临近自行车道的住宅增值预期在 $10 \%$ 以上 ; “可步行性” 和 “可自行车性” 高的地区住宅平均增 值约 34000 美元 ${ }^{[4] 41}$ 。

除加强公交系统可达性之外, 提高公交使用舒适度也很

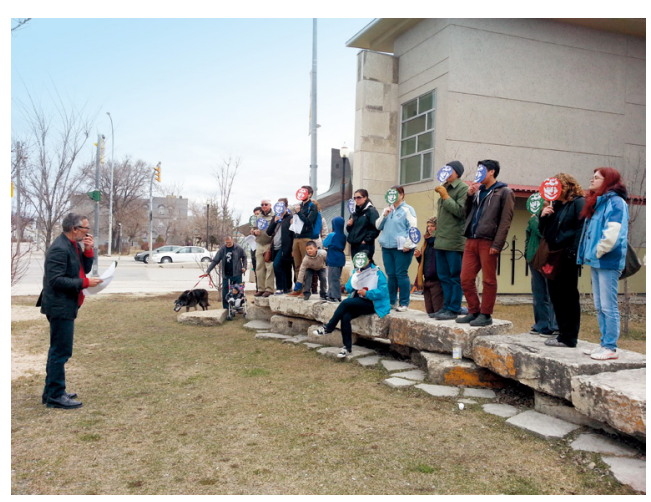

图 3 加拿大温尼伯市的一次 “简之行” 活动 资料来源 : 作者自摄

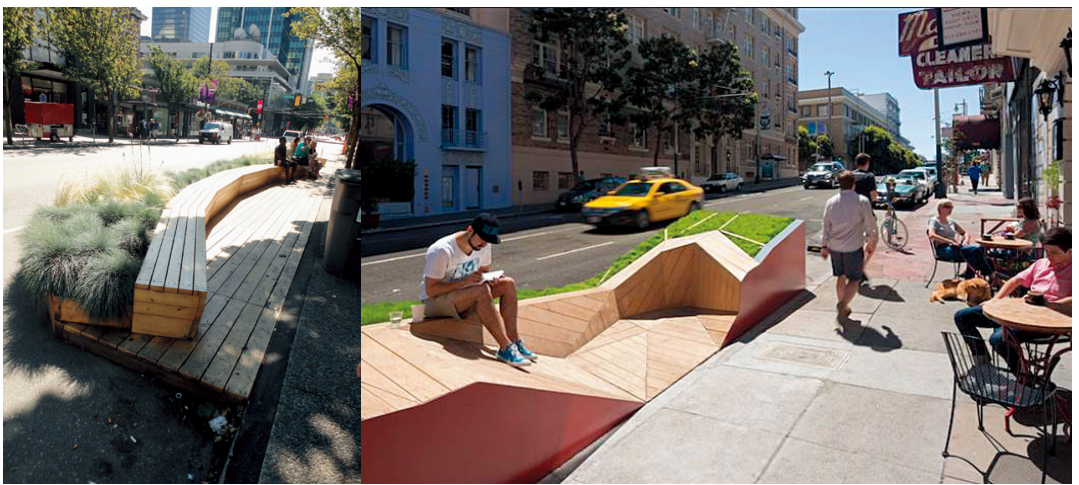

图 4 停车位公园 (左 : 加拿大温哥华市; 右 : 美国旧金山市) 资料来源：(左) 作者自摄；(右) http://ideenapoli.forumfree.it/?t=68796977

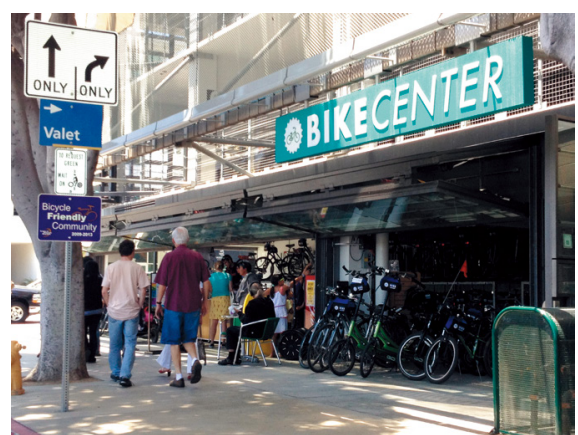

图 5 美国加州圣莫妮卡的自行车中心 资料来源 : http://sdurban.com/?p=1725

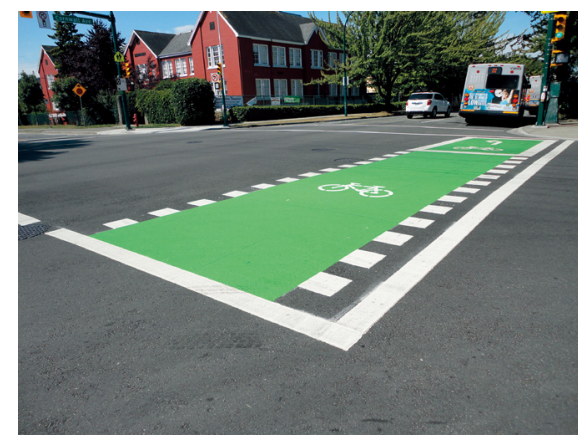

图 6 加拿大温哥华道路交叉口自行车地面标志 资料来源 : 作者自摄

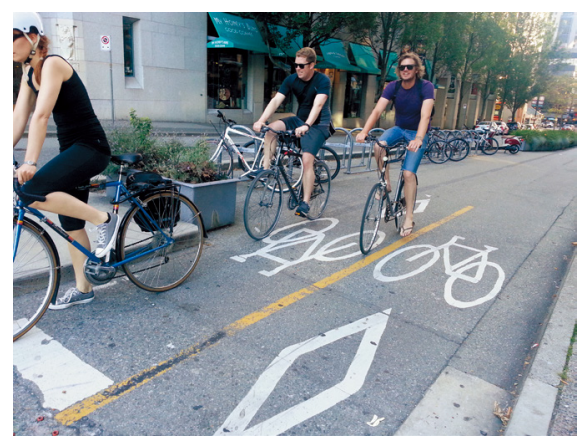

图 7 加拿大温哥华的分离双向自行车道 资料来源 : 作者自摄 
重要。北美的公交车绝大多数是考虑婴儿车和轮椅使用的无 障碍公交车。所有车前都配备可以运送自行车的货架, 方便 选择自行车出行的人搭乘公交车。公交站台配备座椅和遮蔽 设施, 清晰标注公交车到达的准确时间。客流量大的公交站 不是设置港湾而是凸出式站台 (bus bulb) 以保证公交使用 者拥有足够的等待空间 (图 8)。在公交站、重要十字路口 设置行人和自行车路线地图, 标注去往重要目的地或转乘车 站的方向、位置、所需时间、消耗卡路里等信息, 让使用者 一目了然。

适当的停车策略可以用来鼓励除小汽车之外的交通方 式, 比如在公交条件良好的地区减少停车位的设置, 以及通 过 “共享停车位” 和 “共享汽车” 项目帮助减少停车空间需 求。此外, 可适当增收停车费, 其财政收人可用于更积极的 交通方式的建设。

\section{3 积极的公共开放空间}

\section{1 公园和开放空间}

整合大范围地区的步行系统和开放空间, 使之贯穿联通。 梳理通向公园和开放空间的步行和自行车路径, 提高其可见 性、安全性和舒适度。尽量使居民在 10 分钟步行距离范围内 从住处或工作场所能够到达开放空间或者公园。在公园设计 中, 设置鼓励积极生活方式的场所和设施, 如跑步道、游戏场、 运动场地等, 并设置相应的服务设施如洗手间和饮水处。考 虑服务人群的文化偏好, 为所有年龄层次的人群提供运动的 场所和机会。例如, 跨加拿大步道 (Trans Canada Trail) 是 世界上最长的多用途休闲步道, 可以满足徒步、自行车、骑马、 越野滑雪及其他用途的活动。步道横跨加拿大, 从大西洋海 岸到太平洋海岸, 总长将达到 $23000 \mathrm{~km}$, 目前有近 $75 \%$ 的 路段已经相连接, 预计将于 2017 年全部贯通 (图 9)。

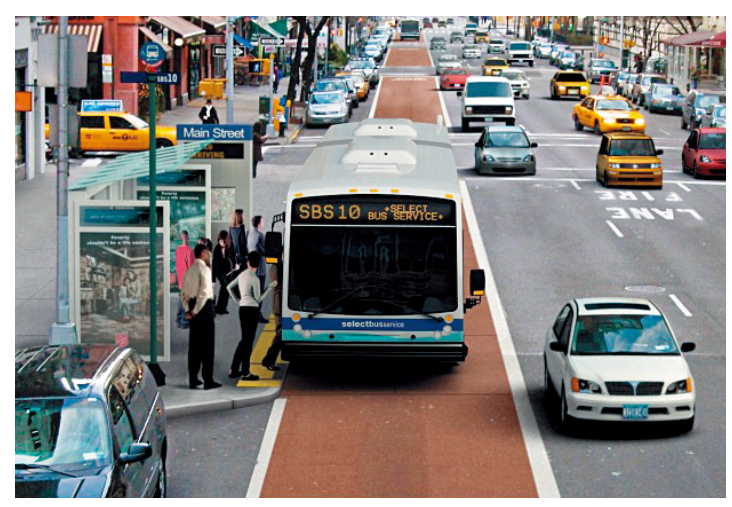

图 8 纽约市的一处凸出式站台

资料来源 : http://www.streetsblog.org/2012/04/26/after-delay-more-improvementscoming-for-east-side-select-bus-service/

\section{2 休闲体育场所}

在社区中心设置充足的休闲体育设施和场地, 并免费或 以很低的收费向所有居民开放。组织各种休闲体育运动, 鼓 励各个年龄阶段的居民参加身体锻炼。大多数的成年人每天 在工作场所至少要度过 8 小时以上的时间, 因而针对工作场 所和雇员健康的项目对于这部分人群至关重要。在工作场所 提供健身场所和项目，通过改善楼梯环境、增加标识等措施 鼓励楼梯使用, 提供弹性的工作时间, 使员工可以相对自由 地安排健身时间。

\section{3 学校和儿童游戏空间}

针对儿童和青少年超重人口比例不断上升、糖尿病患病 率持续增长的趋势, 改变儿童久坐的生活方式, 鼓励他们开 展体育活动并培养健康习惯至关重要。通过体育课程、健康 项目和营养课程, 学校能够帮助年轻人养成受益终生的良好 运动习惯和健康饮食习惯。学校也可以鼓励学生采用步行或 自行车等积极的交通方式上下学, 如在欧美小学有护送儿童 上下学的 “步行校车” 计划, 同时有助于完善学校周边的步 行和自行车环境 (图 10)。学校也是教育和鼓励家庭积极参 加身体锻炼的 “社区联系人”, 有责任组织各种增进健康认 识的项目和活动。同时, 免费开放学校的场地和体育设施, 使学校成为社区活动和锻炼的中心。

儿童游戏空间是保证儿童身体活动的重要场所。具体的 做法包括: 以多样积极的身体活动为主要目的安排儿童游戏 空间，保证居民在合理的步行距离内到达一个免费、专用的 儿童游戏场, 避免国内目前多见的营利性电子娱乐设施; 多 方开发儿童户外活动空间, 如院子、花园、屋顶等; 将自然 要素引人儿童游戏空间; 设计适应不同天气状况的游戏场所, 如设置夏季儿童的戏水场地（图 11）; 增加照明设施, 将游 戏时间延伸到夜晚 ; 在儿童游戏场的地面上标注各种标识以

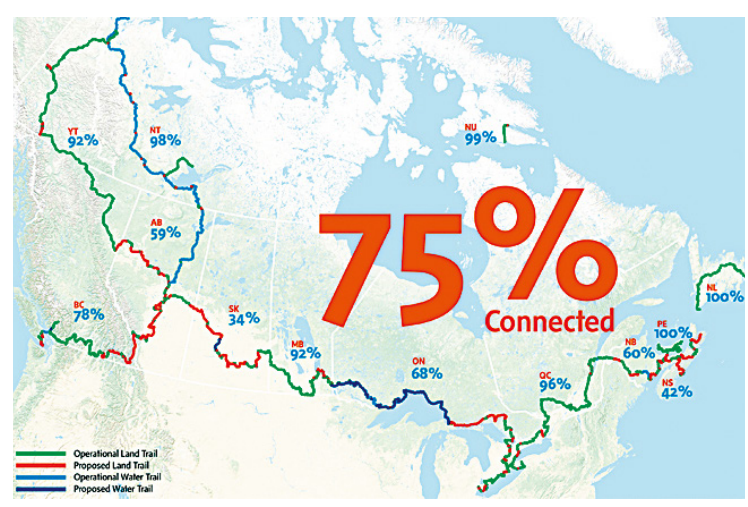

图 9 跨加拿大步道 2014 年已完成 $75 \%$

资料来源 : http://tctrail.ca/assets/Uploads/2014MapBannerPEI100Percent.jpg 
鼓励各种身体活动（图 12）。

\section{4 提供日常锻炼机会的建筑设计}

很多人超过 $90 \%$ 的时间都在室内度过，富有健康理念 的建筑设计能够为健康生活提供更多的选择。将积极设计 哲学融人建筑的交通流线设计, 是鼓励人们在久坐的工作中 得到短暂的运动机会的一个重要方面。爬楼梯是一个被研 究证实能够有效燃烧热量和降低心血管病风险的日常锻炼 机会, 因而在建筑设计中应鼓励至少一个或者多个楼梯的 每日使用, 在少于 4 层的建筑中将楼梯安排在最显眼的位 置, 相对降低电梯位置的可见性, 同时也保障残障人士可 以方便地使用电梯。在高层建筑中, 电梯可根据情况设置 为隔层停靠模式; 除电梯之外应设置供相邻几个楼层使用 的步行楼梯。优化楼梯尺度和环境, 根据使用者的人流量 决定楼梯宽度和设施, 提高楼梯使用空间的环境质量和舒 适度。将楼梯空间作为重点设计和装饰的空间, 引入自然光, 使步行环境更具有吸引力（图 13), 并用标识和广告推广楼 梯的使用, 限制自动扶梯在一般建筑中的使用。在建筑功
能安排中, 将休息室、午餐室或咖啡厅、复印室、收发室、 公用设备间、会议室等空间安排在舒适的步行距离以内, 将 类似的功能组合起来可以有助于创造每日至少 2 次的休息 和行走机会 ${ }^{[5] 68-88}$ 。

在建筑中设置各种支持休闲锻炼和通勤锻炼的设施, 如 在商业和居住建筑中设置健身房、多功能运动空间, 将类似 的空间置于核心易见的位置以鼓励使用; 提供方便自行车通 勤的设施, 如安全的室内自行车存放处、淋浴间和储物柜等, 也有利于鼓励员工在工作的休息间隙进行锻炼 ; 考虑使用者 的不同年龄和需求设置不同类型的活动空间和设施, 如适于 老人的活动室和儿童游戏区等。

建筑外部的体量和细部设计能直接影响街道步行环境质 量, 从而影响人们选择步行的意愿。一个人性化的、丰富多 样并具有连续性的、能够遮风避雨的建筑沿街面, 能够大大 激发人们步行的愿望（图 14）。

\section{5 健康食物的可获得性}

一个社区是否能够以便利的方式获得新鲜的蔬菜水果等

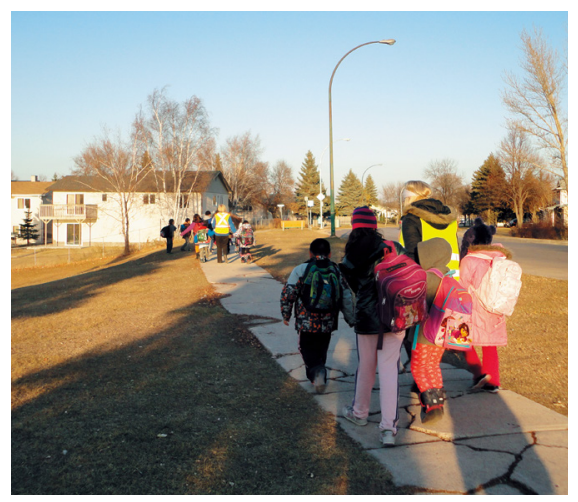

图 10 加拿大温尼伯市的一处 “步行校车” 资料来源 : 作者自摄

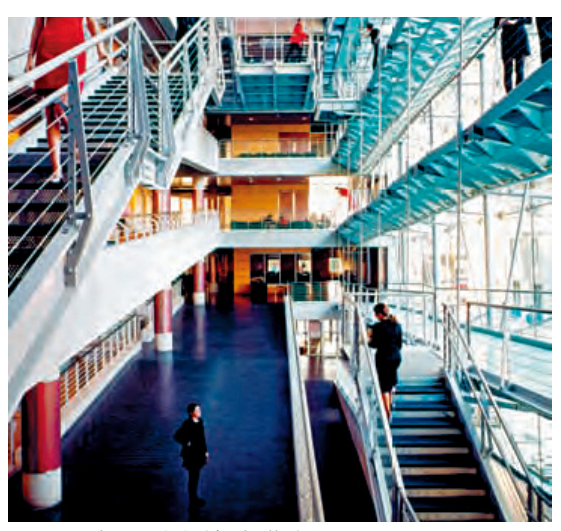

图 13 有吸引力的楼梯空间 资料来源 : 参考文献 [5]
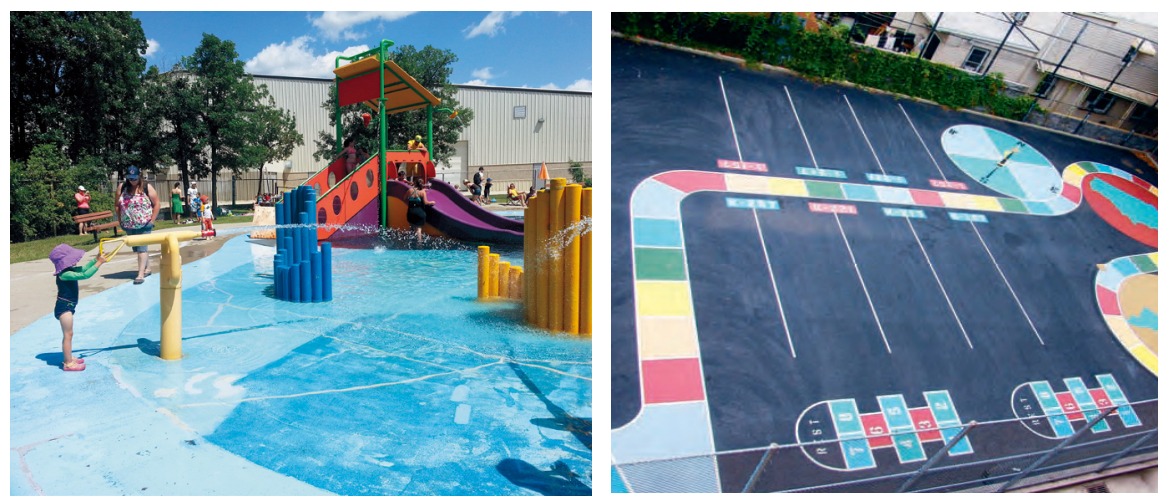

图 11 加拿大温哥华的儿童戏水场 资料来源 : 作者自摄

图 12 儿童游乐场的标记地面 资料来源 : 参考文献 [5]

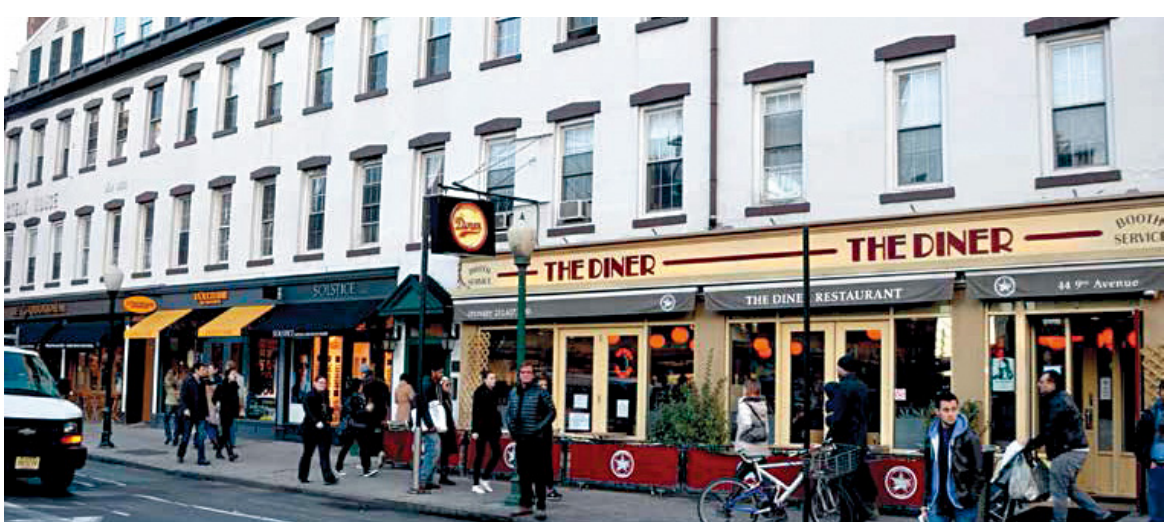

图 14 丰富多样连续的建筑沿街面鼓励步行 资料来源 : 参考文献 [6] 
食品, 在很大程度上会影响社区居民的健康情况。在没有健 康食品选择的时候人们多半会转而消费快餐等不健康饮食, 久而久之患慢性疾病的风险显著提高。尤其在低收人区域, 由于健康食品往往意味着更高的花费, 所以低收人阶层可能 由于无法承担健康食品的支出而产生健康隐患。

为解决这些问题, 很多城市启动了覆盖所有社区的健康 食品推广计划。如纽约市的 “发展食品零售支持健康生活” 行动 (FRESH: Food Retail Expansion to Support Health) 和 新奥尔良市的“新鲜食品零售商计划” (Fresh Food Retailer Initiative), 都鼓励健康食品零售行业的发展。还有一些活 动致力于开发本地自产自销的健康食品, 鼓励发展都市农 业 (urban agriculture) 和社区农业 (community-supported agriculture), 如社区菜园和农民市场等。

都市农业对低收人地区具有特别的重要性。鼓励居民 自己种植健康食物能够有效缓解贫困, 并帮助满足社区 的食品需求。值得一提的是, 美国科罗拉多州的博尔德市 (Boulder) 于 2012 年通过一项区划法的修改决议, 允许 都市农业用地在城市所有类型的区域出现, 包括公园和市 属道路 ${ }^{[4] 60}$, 这一措施在法律层面确立了都市农业用地的 地位。

目前全世界范围内正在掀起一场鼓励本地食物的热潮, 不仅减少对外地外国食物的依赖, 而且能够节约能源, 促进 地方经济发展。例如在欧美很受欢迎的 “社区菜园” 项目, 即社区成员共同在一块园地种植瓜果蔬菜, 享受自产健康食 物的同时也能增进人们的交流和交往 (图 15)。在美国现有 约 18000 个社区菜园, 多由地方政府和非营利组织进行管理。

“农民市场” 是相对于现代的大型零售市场而言的，与后者 不同, 农民直接售卖的食物不需要长途的运输, 品质更新鲜、 品种更多样, 这类似于我国一直使用的农贸市场。农民市场 在美国近年来发展迅速，2006-2013 年，注册的农民市场 的数量增加了一倍, 达到 8000 余处 ${ }^{[4] 63}$ (图 16)。

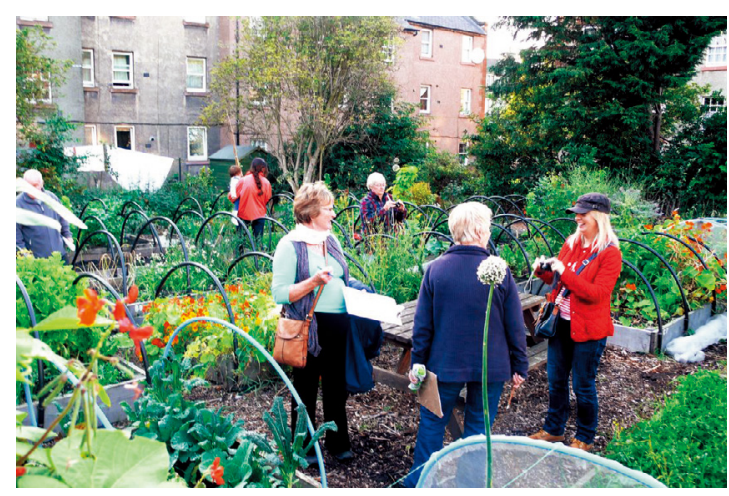

图 15 位于英国爱丁堡的一处社区菜园

资料来源 : http://rcommunitygrowing.ning.com/profiles/blogs/study-tour-to-other-community-gardens

\section{6 社区康体环境评估}

综上所述, 评价一个城市社区是否有利于人们形成积极 的生活方式, 帮助人们改善健康, 可以从用地混合度、街道 慢行环境、城市慢行设施、社会支持、安全性、自然环境和 特殊人群服务等方面进行衡量。具体指标详见表 1 。

\section{7 借鉴和思考}

通过上述社区康体环境评估要素的比较, 对照身边的中 国城市环境, 不难发现与西方发达国家相比, 我们在营造康 体城市的问题上既有自己独特的优势, 也有明显的短板。优 势在于中国城市由于城市规模和人口密度极大, 很少面临困 扰西方尤其是北美的低密度郊区化曼延的问题。集约式的城 市发展在中国不是选择, 而是必须。由此带来的用地相对紧 凑混合、公交优先势在必行, 都是中国城市营造康体城市的 有利方面。另一方面, 中国正处于私家车爆发式发展的阶段, 城市交通系统为满足越来越多的私家车的需要, 很多时候以 牺牲自行车和行人的路权作为代价, 这一现象如今有愈演愈 烈的趋势。当我们惊讶地发现西方对当代私人机动车交通的 反思致使他们的城市仿佛回到了中国满大街都是自行车的 20 世纪七八十年代时, 是否也提醒我们反思如今中国的城市发 展思路和价值观呢?

当然, 中国与西方国家在国情和发展阶段都存在很大不 同。西方发达国家城市化基本完成, 面对过度依赖汽车交通 而造成的城市低密度郊区化蔓延以及能源危机的问题, 全社 会弥漫着对城市可持续发展的紧迫感, 开始反思以汽车为主 导的城市发展模式, 并持续关注健康问题和生活品质问题。 而中国尚处于大规模城市化阶段, 以粗放型发展为主, 能源 利用效率较低, 在健康领域尚处于完善医疗卫生设施、提高 全民医疗服务水平的阶段, 对于城市建成环境对人们健康的 影响尚无清晰认识。就社会意识而言, 我国处于物质生活突

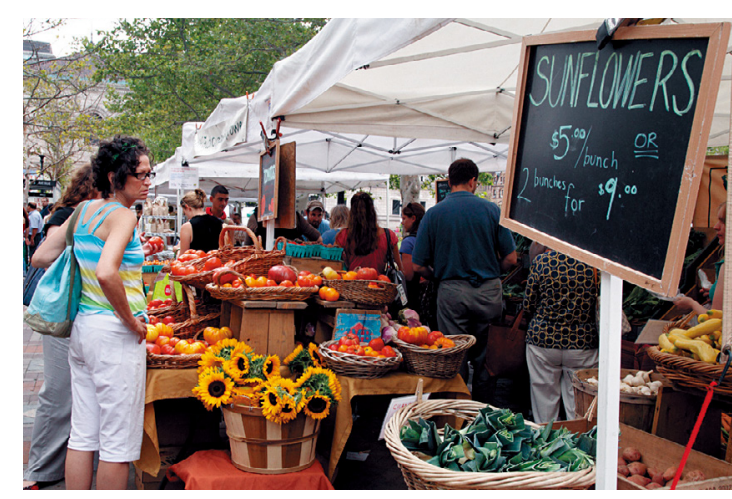

图 16 美国波士顿的一处农民市场

资料来源 : http://commons.wikimedia.org/wiki/File:Copley_Square_Farmer's_Market.jpg 
然丰富的迷茫期, 对生活品质的定义缺乏社会认同, 追求健 康的高品质生活也尚未成为城市规划和城市政策的主流价值 观。另外, 西方尤其是北美由于地广人稀, 需要应对的是低 密度的郊区化蔓延带来的过度依赖小汽车、能耗增加、健康 状况恶化的问题 ; 国内由于人口密度大、土地资源有限, 致 使土地使用效率较高, 但必须面对高密度人口和有限资源带 来的各种医疗服务不足、食品安全威胁、环境污染等问题。 这些都从根源上和现象上造成了中国在康体城市问题上与西 方社会的显著差异。

然而随着机动车交通的迅猛发展, 与西方国家类似的高 能耗、高污染发展方式的弊端逐渐显现，人们过于依赖机动车 缺乏运动而导致健康状况恶化的情况也开始出现。2010-2011 年全国营养与健康状况监测的最新数据表明 : 我国城市居民 的超重率达到 $32.4 \%$, 肥胖率达到 $13.2 \%$ 。更值得关注的是,

\section{表 1 社区康体环境评估}

\begin{tabular}{|c|c|}
\hline 影响 & 观察指标 \\
\hline $\begin{array}{l}\text { 用地混合 : 多 } \\
\text { 样性和可达性 }\end{array}$ & $\begin{array}{l}\text { 距以下地点的距离: 游戏场、工作地、教堂、学校、托儿所、 } \\
\text { 商店、休闲体育设施、公园和绿色空间、非快餐餐厅; } \\
\text { 公交可达性、自行车和步行可达性 }\end{array}$ \\
\hline 街道和步行环境 & $\begin{array}{l}\text { 是否有尽端路、大地块和宽马路； } \\
\text { 小路和连接性线路； } \\
\text { 通往核心地点（公园、学校等）的可选线路； } \\
\text { 沿街绿化和景观； } \\
\text { 是否有随地垃圾和涂鸦； } \\
\text { 住宅、建筑和道路的视觉吸引性； } \\
\text { 是否有破败院落和建筑 }\end{array}$ \\
\hline $\begin{array}{l}\text { 步行和自行车 } \\
\text { 设施 }\end{array}$ & $\begin{array}{l}\text { 是否有人行道; } \\
\text { 人行道的维护情况； } \\
\text { 主要街道是否有自行车道； } \\
\text { 是否有分离的自行车或行人步道； } \\
\text { 是否有免费的城市公共自行车； } \\
\text { 是否有充足安全的自行车停车处； } \\
\text { 是否有遛狗的区域和合适的标识 }\end{array}$ \\
\hline 社会支持 & $\begin{array}{l}\text { 一天中不同时间段和不同日期社区中的步行人数； } \\
\text { 一天中不同时间段和不同日期各地点或设施（如休闲中心、 } \\
\text { 体育设施、公园和学校等）出现的人数 }\end{array}$ \\
\hline $\begin{array}{l}\text { 安全性（道路 } \\
\text { 安全、犯 罪、 } \\
\text { 动物、天气等） }\end{array}$ & $\begin{array}{l}\text { 一天中不同时间段内道路机动车的速度 ; } \\
\text { 是否有斑马线、行人标志和交通稳静化措施； } \\
\text { 一天中不同时刻的照明 (步道、人行道、学校、休闲中心等); } \\
\text { 报告的行人和自行车事故数量 ; } \\
\text { 报告的犯罪数量 ; } \\
\text { 报告的被狗袭击的事故数量 ; } \\
\text { 是否出现社区警察； } \\
\text { 是否有 “邻里守望” 项目 }\end{array}$ \\
\hline 自然环境可达性 & 是否有可用的通往水岸、森林、河流等周边自然环境的路径 \\
\hline 特殊人群服务 & $\begin{array}{l}\text { 是否有为儿童和年轻人设置的积极活动空间和社会支持项目; } \\
\text { 是否有老年人的积极社会交往机会； } \\
\text { 是否有残疾人可用的活动空间和社会支持项目 }\end{array}$ \\
\hline
\end{tabular}

资料来源 : 参考文献 [6]
城市儿童的超重和肥胖率显著增加, 代谢综合症的患病几率 也大大增加。从城市居民慢性病流行情况来看, 高血压患病 率增长, 糖尿病、血脂异常的患病率也有增加 ${ }^{[7]}$ 。可见, 中 国城市健康问题已出现了与西方类似的趋势, 借鉴西方的康 体城市相关做法是相当具有积极意义的。

\section{1 设计层面}

在具体的设计层面, 以下几个方面应特别引起重视。

首先是对城市慢行环境的切实关注。在城市用地有限、 道路空间有限的情况下, 发展的优先权是赋予机动车还是慢 行系统是涉及价值观的深层问题。“以人为本” 具体到城市 发展的选择上, 是必须有所 “舍”, 才能有所 “得” 的。在 很多情况下, 只有 “舍” 掉无序扩张的私人机动车和盲目为 之服务的各种机动车交通, 才能 “得” 到安全的、人性化的、 健康的慢行环境。

其次是对传统概念中健康设施设计的拓展。并非只有体 育馆、运动场、健身房才是健康设施, 以康体为出发点的富于 积极设计的城市, 整个城市就是一个大型的、综合的健康设施, 人们不仅能够锻炼体隗, 更能增进社会交往, 获得社会支持, 达到身心和谐健康的境界。尤其对于与城市环境塑造息息相关 的从业人员, 如城市规划师、交通规划师、建筑设计师等, 意 识到自己的选择会在多大程度上作用于城市建成环境, 并对人 们的健康造成怎样的有利或不利影响是至关重要的。

最后是对弱势群体的充分关照。儿童、老人、残疾人、 少数族裔、低收人人群等弱势群体应该获得同等的设施、场地, 享有同样的康体服务。城市是为人而建, 生活在其中的人的 生活质量是城市空间质量的唯一标准, 所有市民都应有均等 的机会参加利于身心健康的各种活动, 无论性别、年龄、种族、 收人水平或能力。这恐怕应是康体城市给予我们的最大启示。

\section{2 政策理念层面}

城市规划和设计的价值观反映城市发展的水平和社会内 在的价值诉求。在中国和西方城市发展史上, 不同的城市发 展阶段对应着不同的城市价值观。中国皇权时代的城市体现 的是君主意志, 西方早期现代城市曾体验过单纯强调美学因 素的城市美化运动和片面依赖功能分区的不同价值理念。时 至今日, 国际城市规划界普遍强调的是人本价值和公平原则。 以人为本的城市所关注的是如何通过政策、管理和规划设计, 协调社会多方利益, 提高城市空间质量和服务能力, 从而切 实改善每一个 “人” 的生活品质。从社区规划到健康城市, 从生态城市到智慧城市, 其研究都是紧紧围绕着人的核心展 开的。相比而言, 国内城市规划和建设要么倾向于物质环境 的表象, 要么满足于新理念新概念空泛的描述, 而忽略了对 
人的问题的深人研究。对于中国目前的城市发展而言, 确立 人本价值指导城市规划和建设, 是进一步提高城市品质的关 键所在, 也是中国的城市化进程从外延扩张发展到内涵优化 的必经之路。如何 “以人为本”, 在哪些方面真正做到 “以 人为本”, 是将口号变为行动的关键问题。在这一点上, 关 注人们身心健康问题的西方健康城市和康体城市能够给子我 们相当的启示。

在如何落实康体城市理念的问题上, 学界广泛而严谨的 跨学科交叉研究和执行层面多方部门协同是高效达成目标的 必要手段。

以康体城市和积极设计的先行者纽约市为例, 为缓解日 益严重的肥胖症以及慢性病大流行的问题, 由学界自发或者 政府主导形成了多个包括健康、规划、政策、交通、建筑以 及建造专业的跨学科研究团队, 经过多年的学科交叉研究, 获得确丵而丰硕的研究成果。其中一项研究表明, 在采取了 相关的积极设计策略之后, 自 2007-2011 年纽约市的儿童 肥胖症的比例下降了 $5.5 \%$ 。这些成果帮助提高了全社会对 建成环境影响健康问题的认识, 并获得了广泛关注。随后, 纽约市政府于 2012 年成立了跨部门的肥胖症协作组（Multiagency Obesity Task Force) 以促进政府各部门的协调。在该 组织的努力下, 纽约市政府成立了一个推行积极设计的非营 利机构 “积极设计中心” (Active Design Center) 以研究和推 广积极设计领域的相关成果, 并发布了一条要求纽约所有市 属机构必须使用积极设计策略的法令 ${ }^{[8]}$ 。

比较中国目前的情况, 健康领域和城市规划的学科交叉 研究还处于萌芽阶段, 健康问题与城市的关系还极少被官 方和学界提及与讨论, 中国的健康城市发展还有很长的路 要走。UP

\section{参考文献}

[1] WHO. Constitution of the World Health Organization[C] // WHO Basic Documents, 40th ed. Geneva: World Health Organization, 1994.

[2] 许从宝. 健康城市与健康城市规划一一当代国际健康城市运动基本理 论引介与研究 [D]. 南京 : 东南大学, 2006 .

[3] 许从宝, 仲德芘, 李娜. 当代国际健康城市运动基本理论研究纲要 [J]. 城市规划, 2005(10): 52-59.

[4] Urban Land Institute .Intersections: Health and the Built Environment[R]. Washington, DC: Urban Land Institute, 2013.

[5] New York City. Active Design Guidelines: Promoting Physical Activity and Health in Design [R]. City of New York: 2010.

[6] Edwards P, Tsouros A D. A Healthy City is an Active City: A Physical Activity Planning Guide[M]. Copenhagen: WHO Regional Office for Europe, 2008.

[7] 王薇. 第五次中国居民营养与健康状况监测情况显示: 城市居民超重 率超三成, 九成人摄钙量严重不足 [N]. 吉林日报, 2013-5-20(3).

[8] The City of New York. Mayor Bloomberg Announces First Ever Center for Active Design Which Will Promote Physical Activity and Health in Buildings Public Places[EB/OL]. [2013-07-16]. http://www1.nyc.gov/ office-of-the-mayor/news/250-13/mayor-bloomberg-first-ever-centeractive-design-promote-physical-activity-and.

(本文编辑：秦潇雨) 